\title{
How influential is negative informational influence? Evidence from online consumer changes in attitudes
}

\author{
Meng-Lin Shih, *Shu-Hui Chuang \\ Department of Information Technology, Ching Kuo Institute of Management and Health, Fu Hsin Rd., Keelung \\ 20301, Taiwan \\ mlshih@ems.cku.edu.tw \\ *Department of Business Administration, Asia University, Liufeng Rd., Wufeng, Taichung, Taiwan 41354 \\ joyce@asia.edu.tw
}

\begin{abstract}
While marketing scholars have emphasized the importance of informational influence, our understanding of how influential unfavorable information is still remains fragmental. The purpose of this study is to examine the direct and indirect impact of negative informational influence on consumer attitude toward e-commerce acceptance. We seek to prove that negative information about an e-vendor is composed largely of unfavorable reviews regarding product quality, product price, vendor's after-sales service, and vendor's trustworthiness, and not only has a direct effect on consumers' attitude toward the acceptance of that e-vendor, but also has an indirect effect on such attitude via their detrimental beliefs of perceived product quality, perceived price, perceived after-sales service, and consumer trust in vendor. Detailed findings and implications for academics and practitioners are presented
\end{abstract}

\section{Keywords}

negative informational influence, consumer attitude change, consumer acceptance of e-commerce

\section{Introduction}

In the classical literature of consumer behavior, informational influence had been found to affect consumer decision processes regarding product evaluations (e.g., Burnkrant and Cousineau 1975; Cohen and Golden 1972; Pincus and Waters 1977) and product/brand selections (e.g., Bearden and Etzel 1982; Parkand and Lessig 1977). The subsequent research in the contexts of traditional word-of-mouth (WOM) (e.g., Brown and Reingen 1987; Herr et al. 1991; Reingen and Kernan 1986; Richins 1983) and electronic word-of-mouth (eWOM) (e.g., Lee et al. 2008; Park and Lee 2008; Park and Kim 2008; Park et al. 2007) also believed that informational influence such as experiences, evaluations, and/or opinions about a product exerts a strong impact on the purchase judgment of that product. However, how informational influence affects consumers is related to the valence of information (i.e., positive information vs. negative information) they are exposed to. It is generally believed that positive information may function as recommender of a product and facilitate consumers to develop a favorable perception of that product. Negative information, on the contrary, can disparage a product and is thus an important cause that consumers form an unfavorable attitude toward the product they intend to purchase. Because negative information is considered more influential than positive information (Maheswaran and Meyers-Levy 1990; Mizerski 1982; Park and Lee 2009; Wright 1974), negative informational influence is thus chosen by the current study to analyze its impact on online consumers' attitudes.

In examining the impact of negative informational influence, past research typically sought evidence of whether unfavorable information about a product has a direct effect on overall attitude toward that product (e.g., Charlett et al. 1995). While of great significance, such evidence is fragmental and even ill-considered because of the following two reasons. First, it ignores that attitude is a broad construct consisting of different related components, and the overall attitude toward a product may also be the indirect outcome of unfavorable information about that product through other components such as consumer beliefs of that product (e.g., beliefs related to product quality and product price). Next, consumers' attitude arises out of their evaluation not only about the product they want to buy, but also about the vendor they deal with. Under the premise the previous evidence is so shaky that it can't tell us how influential the unfavorable information is. Therefore, taking above reasons into account, the current study seeks to prove that negative information about an e-vendor is composed largely of unfavorable reviews regarding product quality, product price, vendor's aftersales service, and vendor's trustworthiness, and may thus not only have a direct effect on consumers' attitude toward the acceptance of that e-vendor, but also have an indirect effect on such attitude via their detrimental beliefs related to product or vendor, namely perceived product quality, perceived price, perceived after-sales service, and consumer trust in vendor.

\section{Theoretical background}

\section{Informational social Influence}

Deutsch and Gerard (1955) distinguished two types of social influence: (1) normative influence, which occurs when individuals conform to the expectations of others, and (2) informational influence, which occurs when individuals accept information from others as evidence of reality. The current study primarily focuses on the influential ability of informational influence in the formation of consumers' beliefs and attitudes toward e-vendor acceptance. We specifically choose informational influence rather than normative influence because of the following two reasons. (1) While normative 
influence (e.g., subjective norm, social norm) has been dominantly used to capture the essence of social influence and examine its influence on technology acceptance behavior, it has only a significant influence on technology acceptance under mandatory settings (Venkatesh and Davis 2000). That is, normative influence is nonsignificant in the voluntary behavior such as consumers' acceptance of e-vendor. (2) It is believed that when a person is placed in a product evaluation situation in which he is unable to adequately assess the characteristics of the product from direct observation and contact, he will view the reactions of others as evidence about the true nature of the product (Burnkrant and Cousineau 1975). Unlike offline vendor, online vendor is an environment where consumers can not depend on all five senses to evaluate products and make purchases, so we believe that informational influence is more likely to play an important role than normative influence in the formation and change of consumers' attitude and beliefs regarding the acceptance of e-vendor.

\section{Consumer changes in attitudes}

Attitude has been viewed as a broad construct consisting of different related components in the social psychology research. In particular, the tripartite theory of attitudes postulates that attitudinal responses can be classified into affective, cognitive, and behavioral (or conative) categories (Katz and Stotland 1959; Rosenberg and Hovland 1960; Zanna and Rempel 1988). Empirical evidence has also supported the notion that an individual's evaluative judgments about a given object can be reflected in affective, cognitive, and behavioral dimensions (Breckler 1984; Kothandapani 1971; Ostrom 1969). Therefore, the current study attempts to include two of the three dimensions of attitudinal responses: attitude (affect) and belief (cognition) to explore their changes as the result of exposure to the negative informational influence. We believe that whichever attitude it is in nature, it will be changed directly and/or indirectly after the presentation of the negative persuasive information. This will help us understand how damaging such information is to the reputation of an evendor.

\section{Research hypotheses}

As mentioned above, no matter which attitude it is, it will be susceptible directly and/or indirectly to negative informational influence. The question now is, however, which is susceptible directly to such influence and which is susceptible indirectly to. According to existing attitude theories such as the theory of reasoned action (TRA) (Fishbein and Ajzen 1975) and the theory of planned behavior (TPB) (Ajzen 1991), belief (cognition) influences attitude (affect) regarding a target behavior. The technology acceptance model (TAM) (Davis et al. 1989) also suggests that users' IT acceptance attitude is shaped directly by salient user belief (i.e., perceived usefulness). Therefore, we hypothesize that negative informational influence not only have a direct effect on consumers' attitude toward the acceptance of that e-vendor, but also have an indirect effect on such attitude via their detrimental beliefs related to product or vendor, namely perceived product quality, perceived price, perceived after-sales service, and consumer trust in vendor. Followings are the hypotheses:

H1. Negative information is negatively associated with consumers' attitude toward e-vendor acceptance.

H2. Negative information is negatively associated with consumers' perceived product quality from e-vendor.

H3. Negative information is negatively associated with consumers' perceived after-sales service from e-vendor.

H4. Negative information is negatively associated with consumers' perceived product price from e-vendor.

H5. Negative information is negatively associated with consumers' trust in e-vendor.

H6. Consumers' perceived product quality from e-vendor is positively associated with their attitude toward e-vendor acceptance.

H7. Consumers' perceived after-sales service from e-vendor is positively associated with their attitude toward e-vendor acceptance.

H8. Consumers' perceived product price from e-vendor is positively associated with their attitude toward e-vendor acceptance.

H9. Consumers' trust in e-vendor is positively associated with their attitude toward e-vendor acceptance.

\section{Research methodology}

\section{Data Collection}

We administrate a procedure of data collection that comprises a questionnaire survey of two time periods and a reading program of negative online consumer reviews. First, consumers are given the first-period questionnaire online for collecting the demographic data and their self-reported perceptions related to the last acceptance with the e-vendor they visited and purchased products most frequently. The perceptions include how their beliefs of, and attitude toward, that $e$ vendor acceptance are row. Next, those who complete the first-period questionnaire require reading negative consumer reviews for administrating the second-period questionnaire. They are asked to key in a given Web URL in the address bar of Web browser and then press the enter key, which directs them to the Web pages of negative reviews. On those Web pages, four different sets of negative consumer reviews related to their beliefs of that e-vendor acceptance (each set of reviews is related to each belief mentioned earlier) are presented sequentially. When respondents are exposed to each set of reviews, they are first asked to report how influential they perceive of that set of reviews. Their belief of that evendor acceptance is then reported in response to the presentation of that set of reviews. Finally, consumers are 


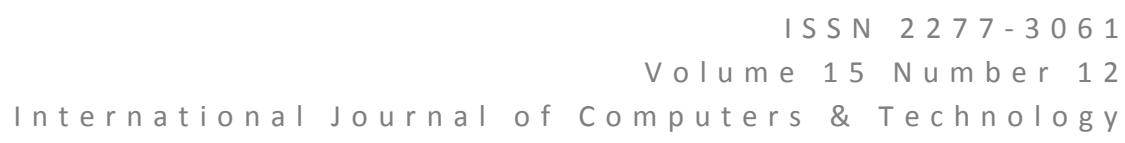

requested to assess how influential they perceive of these four sets of reviews in general; at the same time their attitude toward the e-vendor acceptance is assessed again for reflecting the influence by negative persuasive message and ending the whole procedure of data collection.

\section{Questionnaire Development}

Six core constructs are proposed in the current study: (1) attitude toward e-vendor acceptance, (2) perceived product quality, (3) perceived after-sales service, (4) perceived price, (5) consumer trust in vendor, and (6) perceived influence of negative information. All six constructs are quantified on the basis of multiple items validated in prior research, which are reworded to relate specifically to the context of e-commerce acceptance.

Attitude toward e-vendor acceptance is adapted from Bhattacherjee and Premkumar's (2004) attitude toward IT usage, and is measured using a four-item semantic differential scale anchored between adjective pairs "bad idea...good idea," "foolish move...wise move," "negative step...positive step," and "ineffective idea...effective idea." Perceived product quality refers to the consumer's judgment about a product's overall excellence or superiority in terms of its reliability, dependability, durability, and quality (Zeithaml 1988), and is measured using four Likert-scaled items adapted from Dodds et al. (1991). Perceived after-sales service is measured using three Likert-scaled items adapted from Koo et al.'s (2008) scale that examines consumers' perceptions of whether the e-vendor can deliver the right products ordered, whether the e-vendor can deliver the products ordered at promised time, and whether returning or exchanging harmed product from the e-vendor is easy. The scale for perceived price are three items and adapted from Gupta and Kim's (2007) seven-point Likert scale that reflects consumers' perception of whether they get a lower price when purchasing products with the evendor. Consumer trust in vendor focuses on privacy trust and refers to the extent to which consumers believe that the actual e-vendor could protect their personal information by not selling it to third parties without their permission. The scale for this construct consists of two Likert-scaled items drawn from Malhotra et al.'s (2004) scale of information privacy concerns. The construct designated as perceived influence of negative information is measured using a three-item semantic differential scale adapted from O'Keefe (2002) and Zhang et al. (2010), which evaluates consumers' perception of whether the reviews they read are persuasive, convincing, and influential.

\section{Data analysis and results}

\section{Respondents Profile}

Two hundred and ten consumers were recruited to take part in the procedure of data collection. All of them are voluntary and highly motivated to spend a little time to participate in reading the reviews regarding the e-vendor they shopped most frequently and filling out the two-period questionnaires. However, since they referred to as much as four different sets of negative reviews, it is unavoidable that there are subjects who did not complete all the questionnaires after using the last six digits of the respondents' mobile phone numbers for matching their answers across the two periods of data collection. We thus eliminate 52 of such subjects from the original intended samples and a total of 158 effective responses were obtained for data analysis.

Of the eligible respondents, the number of male was approximately twice as much as that of female. Nonetheless, we do not consider this heterogeneity a concern because the stimuli of attitude changes, i.e. persuasive messages, are not different for male compared to female consumers. In addition, the majority of the eligible respondents are between 20 and 29 years old, and such respondents do not include a wide age-range of online consumers. Even so, it was not a matter to the main effects of this study because these young persons in their twenties are of the attributes of the target populationthey have purchased products online and are among the potential group of the readers of online reviews. Detailed demographic data and profile about these usable respondents are shown in Table 1.

Table 1. Respondents Profile

\begin{tabular}{llll}
\hline Characteristic & Description & Frequency & Percentage \\
\hline Gender & Male & 106 & $67 \%$ \\
& Female & 52 & $33 \%$ \\
Age & Under 20 & 28 & $18 \%$ \\
& $20-29$ & 114 & $72 \%$ \\
& $30-39$ & 6 & $4 \%$ \\
& $40-49$ & 8 & $5 \%$ \\
& Over 50 & 2 & $1 \%$ \\
E-Vendor* & & & \\
& Yahoo! & 114 & $72 \%$ \\
& PChome & 10 & $6 \%$
\end{tabular}


Table 1. Respondents Profile

\begin{tabular}{llll}
\hline Characteristic & Description & Frequency & Percentage \\
\hline & momo & 4 & $3 \%$ \\
& books & 14 & $9 \%$ \\
& 7net & 4 & $3 \%$ \\
& PayEasy & 2 & $1 \%$ \\
& Others & 10 & $6 \%$ \\
& & & \\
Frequency of Purchase\# & $1-2$ & 49 & $31 \%$ \\
& $3-4$ & 25 & $16 \%$ \\
& $5-6$ & 36 & $23 \%$ \\
& $7-8$ & 18 & $11 \%$ \\
& $9-10$ & 11 & $7 \%$ \\
& $11-12$ & 1 & $1 \%$ \\
& Over 12 & 18 & $11 \%$
\end{tabular}

* Answers represent the e-vendors respondents used for product purchase most frequently.

\# Answers were based on the number of times respondents purchased products from the most frequently used e-vendor within the past one year.

\section{Hypotheses Testing}

To verify that online consumers do change their attitudes after the presentation of negative persuasive messages, we require comparing subjects' responses of the focal constructs (i.e., attitude and beliefs) at two different periods in time (t 1 and t2). As the information shown in Table 2, we aggregated item responses for the constructs of attitude and four beliefs at the two periods in time and compared the mean aggregated scores by performing a series of paired t-tests in the software of SPSS. From this table, subjects' mean scores of the focal constructs are all dropped from time t1 to time t2 with the minimum t-value being 10.609 or $p$-value being 0.000 , demonstrating that consumers' perceptions (i.e., attitude and beliefs) regarding e-commerce acceptance do change when they are exposed to negative persuasive messages.

Table 2. Comparison of Attitudes

\begin{tabular}{|c|c|c|c|c|c|c|c|c|c|}
\hline & & $\mathrm{t} 1$ & & t2 & & Diff $(t$ & & & \\
\hline Construct ${ }^{*}$ & $\mathrm{~N}$ & Mean & S.D. & Mean & S.D. & Mean & S.D. & $\mathrm{t}$-value & Sig. \\
\hline ATT1 ATT2 & 158 & 5.21 & 1.03 & 4.13 & 1.09 & 1.07 & 1.08 & 12.502 & .000 \\
\hline Q1 Q2 & 158 & 5.10 & 1.01 & 3.58 & 1.35 & 1.51 & 1.12 & 16.916 & .000 \\
\hline $\begin{array}{ll}\text { S1 } & \text { S2 }\end{array}$ & 158 & 5.17 & 1.03 & 3.94 & 1.28 & 1.23 & 1.07 & 14.494 & .000 \\
\hline $\begin{array}{ll}\text { P1 } & \text { P2 }\end{array}$ & 158 & 4.83 & 1.03 & 3.73 & 1.16 & 1.10 & 1.10 & 12.615 & .000 \\
\hline $\begin{array}{ll}\text { TRINV1 } & \text { TRINV2 }\end{array}$ & 158 & 4.64 & 1.24 & 3.70 & 1.34 & 0.94 & 1.11 & 10.609 & .000 \\
\hline
\end{tabular}

* ATT: attitude; Q: Product Quality; S: After-Sales Service; P: Product Price; TRINV: Trust in Vendor

To further verify the direct and/or indirect impact of negative informational influence, the following move for data analysis is to examine the significance and strength of each of the hypothesized effects using the partial least square (PLS) approach. SmartPLS Version 2.0.M3 software (Ringle et al. 2006) was used for this purpose. These results, including standardized path coefficients, path significances, and variance explained (R2 values) of dependent constructs. As shown in our data, product quality, after-sales service, product price, and trust in vendor are all explained by negative persuasive

message (the lowest being -0.319 at $p$-value $<0.001$ for trust in vendor), suggesting that these product- and vendorrelated beliefs are easily susceptible to negative informational influence; therefore, $\mathrm{H} 2, \mathrm{H} 3, \mathrm{H} 4$, and $\mathrm{H} 5$ are supported by 
the empirical evidence. About 77 percent of the attitude variance is explained jointly by product quality $(=0.365$, $\mathrm{p}$ value $<0.01)$, after-sales service $(=0.206$, $\mathrm{p}$-value $<0.05)$, product price $(=0.249$, $\mathrm{p}$-value $<0.01)$, trust in vendor (

$=0.094$, p-value $<0.1)$, and negative persuasive message $(=-0.140$, p-value $<0.1)$, suggesting that all the productand vendor-related beliefs are crucial for the formation of attitude toward e-commerce acceptance; therefore, the hypotheses of $\mathrm{H} 1, \mathrm{H} 6$ through $\mathrm{H} 9$ are all supported by the empirical evidence. A summary of the results of hypotheses testing is presented in Table 3.

Table 3. Results of Hypotheses Testing

\begin{tabular}{|c|c|c|c|}
\hline Hypothesis & Path & Path Coefficient & Support \\
\hline $\mathrm{H} 1$ & N. Info. Influence -> Attitude & $-0.140+$ & Yes \\
\hline $\mathrm{H} 2$ & N. Info. Influence -> Product quality & $-0.648^{* * *}$ & Yes \\
\hline H3 & N. Info. Influence -> After-sales service & $-0.573^{\star \star *}$ & Yes \\
\hline $\mathrm{H} 4$ & N. Info. Influence -> Product price & $-0.672^{\star \star \star}$ & Yes \\
\hline H5 & N. Info. Influence -> Trust in vendor & $-0.319^{* \star *}$ & Yes \\
\hline $\mathrm{H} 6$ & Product quality $->$ Attitude & $0.365^{\star *}$ & Yes \\
\hline $\mathrm{H} 7$ & After-sales service $->$ Attitude & $0.206^{*}$ & Yes \\
\hline $\mathrm{H} 8$ & Product price -> Attitude & $0.249^{\star *}$ & Yes \\
\hline H9 & Trust in vendor $->$ Attitude & $0.094+$ & Yes \\
\hline
\end{tabular}

Path significance: ${ }^{* \star} \mathrm{P}<.001 ;{ }^{* *} \mathrm{P}<.01 ;{ }^{*} \mathrm{P}<.05 ;+\mathrm{P}<.1$

R2 values:

product quality: 0.746; after-sales service: 0.665 ; product price: 0.699 ;

trust in vendor: 0.504; attitude: 0.772

\section{Discussion and Conclusions}

The purpose of this study is to examine how influential negative informational influence is. Evidence from online consumers' changes in beliefs and attitude tells the truth. Specifically, such evidence is more comprehensive since it arouses that the overall attitude toward a product may also be the indirect outcome of unfavorable information about that product through other intervening variables such as consumer beliefs of that product. As noted by WOM literature, unfavorable information about a product generally represents a consumer response to her/his dissatisfaction with that product's quality, service, price, and so on, and may thus be of an indirect influence on other prospective consumers' attitude toward that product via their perceptions of that product's quality, service, price, and so on. Therefore, we argue that negative information on an online shopping channel is composed largely of unfavorable reviews regarding product quality, after-sales service, product price, and vendor trustworthiness, and may thus not only have a direct effect on experienced consumers' attitude toward that channel's usage, but also have an indirect effect on such attitude via their detrimental beliefs related to product quality, after-sales service, product price, and vendor trustworthiness. That is, even though consumers have been satisfied with prior usage of an e-vendor, if they are exposed to unfavorable reviews, then they are likely to develop an unfavorable attitude toward that e-vendor usage immediately (revisiting that e-vendor for the purchase of products is not a good/wise idea). Nevertheless, consumers are also likely to form their detrimental beliefs before form unfavorable attitude toward that e-vendor usage under the circumstance where they are exposed to unfavorable reviews. That is, that e-vendor is not trustworthy in its capability of protecting consumers' private information, that e-vendor's products are not of better quality and lower price, and that e-vendor does not provide a good after-sales service to the products purchased, so that e-vendor for the purchase of products is not a good/wise idea. Above results will bring a contribution to academics and practitioners in the area of e-commerce acceptance. 


\section{REFERENCES}

I. Ajzen, I. "The Theory of Planned Behavior," Organizational Behavior and Human Decision Processes (50), 1991, pp.179-211.

II. Bearden, W. O., and Etzel, M. J. "Reference Group Influence on Product and Brand Purchase Decisions," Journal of Consumer Research (9:2), September 1982, pp. 183-194.

III. Bhattacherjee, A., and Premkumar, G. "Understanding Changes in Belief and Attitude toward Information Technology Usage: A Theoretical Model and Longitudinal Test," MIS Quarterly (28:2), June 2004, pp. $229-254$.

IV. Breckler, S. J. "Empirical Validation of Affect, Behavior, and Cognition as Distinct Components of Attitude," Journal of Personality and Social Psychology (47:6), 1984, pp. 1191-1205.

V. Brown, J. J., and Reingen, P. H. "Social Ties and Word-of-Mouth Referral Behavior," Journal of Consumer Research (14), December 1987, pp. 350-362.

VI. Burnkrant, R. E., and Cousineau, A. "Informational and Normative Social Influence in Buyer Behavior," The Journal of Consumer Research (2:3), December 1975, pp. 206-215.

VII. Charlett, D., Garland, R., and Marr, N. "How Damaging is Negative Word of Mouth?" Marketing Bulletin (6), May 1995, pp. 42-50.

VIII. Cohen, J. B., and Golden, E. "Informational Social Influence and Product Evaluation," Journal of Applied Psychology (56:1), February 1972, pp. 54-59.

IX. Davis, F. D., Bagozzi, R. P., and Warshaw, P. R. "User Acceptance of Computer Technology: A Comparison of Two Theoretical Models," Management Science (35:8), 1989, pp. 982-1003.

X. Deutsch, M., and Gerard, H. B. "A Study of Normative and Informational Social Influence upon Individual Judgment," Journal of Abnormal \& Social Psychology (51:3), 1955, pp. 629-636.

XI. Dodds, W. B., Monroe, K. B., and Grewal, D. "Effects of Price, Brand, and Store Information on Buyers' Product Evaluations," Journal of Marketing Research (28:3), August 1991, pp. 307-319.

XII. Fishbein, M., and Ajzen, I. Belief, Attitude, Intention, and Behavior: An Introduction to Theory and Research, Addison-Wesley, MA, 1975.

XIII. Gupta, S., and Kim, H.-W. "The Moderating Effect of Transaction Experience on the Decision Calculus in On-Line Repurchase," International Journal of Electronic Commerce (12:1), Fall 2007, pp. 127-158.

XIV. Herr, P. M., Kardes, F. R., and Kim, J. "Effects of Word-of-Mouth and Product-Attribute Information on Persuasion: An Accessibility-Diagnosticity Perspective," Journal of Consumer Research (17:4), March 1991, pp. 454-462.

XV. Katz, D., and Stotland, E. "A Preliminary Statement to a Theory of Attitude Structure and Change," in Psychology: A Study of a Science (3), S. Koch (eds.), New York: McGraw-Hill, 1959, pp. 423-475.

XVI. Koo, D.-M., Kim, J.-J., and Lee, S.-H. "Personal Values as Underlying Motives of Shopping Online," Asia Pacific Journal of Marketing and Logistics (20:2), 2008, pp. 156-173.

XVII. Kothandapani, V. "Validation of Feeling, Belief, and Intention to Act as three Components of Attitude and their Contribution to Prediction of Contraceptive Behavior," Journal of Personality and Social Psychology (19), 1971, pp. 321-333.

XVIII. Lee, J., Park, D.-H., and Han, I. "The Effect of Negative Online Consumer Reviews on Product Attitude: An Information Processing View," Electronic Commerce Research and Applications (7:3), Autumn 2008, pp. 341352.

XIX. Maheswaran, D., and Meyers-Levy, J. "The Influence of Message Framing and Issue Involvement," Journal of Marketing Research (27:3), 1990, pp. 361-367.

XX. Malhotra, N. K., Kim, S. S., and Agarwal, J. "Internet Users' Information Privacy Concerns (IUIPC): The Construct, the Scale, and a Causal Model," Information Systems Research (15:4), December 2004, pp. 336-355.

XXI. Mizerski, R. W. "An Attribution Explanation of the Disproportionate Influence of Unfavorable Information," Journal of Consumer Research (9:3), December 1982, pp. 301-310.

XXII. O'Keefe, D. J. Persuasion: Theory and Research, Sage Publications Inc., Thousand Oaks, California, 2002.

XXIII. Ostrom, T. M. "The Relationship between the Affective, Behavioral and Cognitive Components of Attitude," Journal of Experimental Social Psychology (5), 1969, pp. 12-30.

XXIV. Park, C., and Lee, T. M. "Information Direction, Website Reputation and eWOM Effect: A Moderating Role of Product Type," Journal of Business Research (62:1), January 2009, pp. 61-67. 


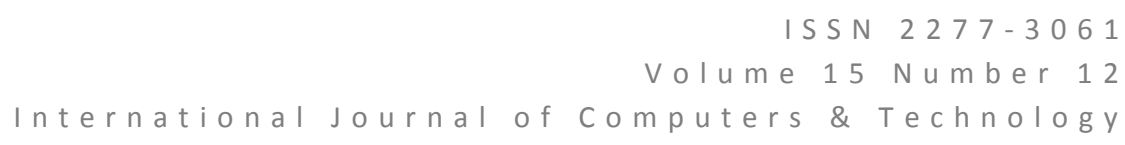

XXV. Park, D.-H., and Kim, S. "The Effects of Consumer Knowledge on Message Processing of Electronic Word-ofMouth via Online Consumer Reviews," Electronic Commerce Research and Applications (7:4), Winter 2008, pp. 399-410.

XXVI. Park, D.-H., and Lee, J. "eWOM Overload and Its Effect on Consumer Behavioral Intention Depending on Consumer Involvement," Electronic Commerce Research and Applications (7:4), Winter 2008, pp. 386-398.

XXVII. Park, D.-H., Lee, J., and Han, I. "The Effect of On-Line Consumer Reviews on Consumer Purchasing Intention: The Moderating Role of Involvement," International Journal of Electronic Commerce (11:4), Summer 2007, pp. 125-148.

XXVIII. Parkand, C. W., and Lessig, P. "Students and Housewives: Differences in Susceptibility to Reference Group Influence," Journal of Consumer Research (4:2), September 1977, pp. 102-110.

XXIX. Pincus, S., and Waters, L. K. "Informational Social Influence and Product Quality Judgments," Journal of Applied Psychology (62:5), October 1977, pp. 615-619.

XXX. Reingen, P. H., and Kernan, J. B. "Analysis of Referral Networks in Marketing: Methods and Illustration,” Journal of Marketing Research (23), November 1986, pp. 370-378.

XXXI. Richins, M. L. "Negative Word-of-Mouth by Dissatisfied Consumers: A Pilot Study," Journal of Marketing (47), Winter 1983, pp. 68-78.

XXXII. Ringle, C. M., Wende, S., and Will, A. SmartPLS Version 2.0.M3, University of Hamburg, Hamburg, 2006.

XXXIII. Rosenberg, M. J., and Hovland, C. I. "Cognitive, Affective, and Behavioral Components of Attitudes," in Attitude Organization and Change, M. J. Rosenberg, C. I. Hovland, W. J. McGuire, R. P. Abelson, and J. W. Brehm (eds.), New Haven, CT: Yale University Press, 1960, pp. 1-14.

XXXIV. Venkatesh, V., and Davis, F. D. "A Theoretical Extension of the Technology Acceptance Model: Four Longitudinal Field Studies," Management Science (45:2), 2000, pp. 342-365.

XXXV. Wright, P. "The Harassed Decision Maker: Time Pressures, Distractions, and the Use of Evidence," Journal of Applied Psychology (59:5), October 1974, pp. 555-561.

XXXVI. Zanna, M. P., and Rempel, J. K. "Attitudes: A New Look at an Old Concept," in The Social Psychology of Knowledge, D. Bar-Tal and A. W. Kruglanski (eds.), New York: Cambridge University Press, 1988, pp. 315-334.

XXXVII. Zeithaml, V. A. "Consumer Perceptions of Price, Quality, and Value: A Means-End Model and Synthesis of Evidence," The Journal of Marketing (52:3), July 1988, pp. 2-22.

XXXVIII. Zhang, J. Q., Craciun, G., and Shin, D. "When Does Electronic Word-of-Mouth Matter? A Study of Consumer Product Reviews," Journal of Business Research (63:12), December 2010, pp. 1336-1341. 